\title{
Optimum Efficiency of PV Panel Using Genetic Algorithms to Touch Proximate Zero Energy House (NZEH)
}

\author{
Bdoor Majed Ahmed ${ }^{a}$, Nibal Fadel Farman Alhialy ${ }^{a^{*}}$ \\ ${ }^{a}$ Energy Department, College of Engineering, University of Baghdad, Baghdad 00964, Iraq.
}

Received 22 February 2019; Accepted 28 June 2019

\begin{abstract}
By optimizing the efficiency of a modular simulation model of the PV module structure by genetic algorithm, under several weather conditions, as a portion of recognizing the ideal plan of a Near Zero Energy Household (NZEH), an ideal life cycle cost can be performed. The optimum design from combinations of NZEH-variable designs, are construction positioning, window-to-wall proportion, and glazing categories, which will help maximize the energy created by photovoltaic panels. Comprehensive simulation technique and modeling are utilized in the solar module I-V and for P-V output power. Both of them are constructed on the famous five-parameter model. In addition, the efficiency of the PV panel is established by the genetic algorithm under the standard test conditions (STC) and a comparison between the theoretical and experimental results is done to achieve maximum performance ranging from 0.15 to 0.16 , particularly with an error of about -0.333 for an experimental power of 30 Watts compared with the theoretical power of 30.1 Watts. The results obtained by the genetic algorithm give the best value for efficiency at the range of $16 \%$ to $17 \%$ of solar radiation, from $500-600 \mathrm{~W} / \mathrm{m} 2$. These values are almost identical to the efficiency obtained from the results of the operation, where the best value for efficiency in the experimental results was seen to be $15.7 \%$.
\end{abstract}

Keywords: Genetic Algorithm; Optimum Efficiency; Photovoltaic Panels; Model of Single-Diode.

\section{Introduction}

Due to the increasing demand for clean and renewable energy applications, to avoid increasing $\mathrm{CO}_{2}$ release into the environment, there is a growing demand for electrical energy, specifically in Iraq. Solar energy is plentiful in Iraq throughout the year. In Iraq, there is a leak in the provision of electricity, especially in the summer season, coinciding with the high rising temperature and increasing demand for cooling. Iraq is qualified to be a producer of all solar applications and is expected to provide solar electricity to its neighbours. Academicians in Iraq have investigated the effects of weather conditions on different solar energy applications in detail and obtained significant results, possibly the crucial point is that the weather conditions in Iraq fit all solar applications [1]. Near Zero Energy House (NZEH) or Net Zero Energy Building (NZEB) design is a housing building that provides energy efficiently by using renewable energy technologies and passive house design. The basic conception of Zero Energy Building (ZEB) is that a building should produce its energy from clean, renewable, and less expensive sources. Presently, the budget for NZEHs is fairly high owing to the high costs of the apparatus and resources for solar sheet, isolation, fenestration, and other renewable energy expertise. As a result, an investigation to attain the optimum design of an NZEH is obligatory. The aim of the optimal design is to accomplish a reasonably priced human life progression budget performance of the NZEH. The Genetic Algorithm is one of the best optimization techniques that can be utilized. It provides a technique to achieve the

* Corresponding author: engineernebal@yahoo.com

http://dx.doi.org/10.28991/cej-2019-03091375

(C) 2019 by the authors. Licensee C.E.J, Tehran, Iran. This article is an open access article distributed under the terms and conditions of the Creative Commons Attribution (CC-BY) license (http://creativecommons.org/licenses/by/4.0/). 
optimal strategy established on the variable design groupings of NZEH. The investigated design parameters include photovoltaic (PV) array efficiency optimization [2,3]. For designing a solar photovoltaic system for a single family dwelling, the civil engineer must design the structural engineering or architecture for PV supplemental information to construct a structure and a roof plan. He has to provide a roof plan projected on a site plan; show the location and dimensions of all solar photovoltaic equipment and PV arrays (Figure 1).

A Photovoltaic generator (PV) is a nonlinear system, because its behaviour depends mainly on environmental circumstances, for instance, radiation, temperature, wind speed, humidity, dust, clouds, etc. Alima (2015) and Zaihidee et al. (2016) have investigated the dependence of PV on the effect of temperature on the output power of different PV modules $[4,5]$. For increasing the quality of the manufactured solar panels, devices, and modelling of the device and its simulators, careful extraction and an improvement of solar panel parameters is required. Direct methods depend on the use of the I-V curve, at specific points, to determine some cell parameters. Consequently the accuracy of these techniques is determined by the accuracy of the measured data and the data processed by the manufacturer, as also the errors made by the numerical and simplified discrimination of formulae used to extract the parameters. Other methods used for extracting solar panel parameters rely on the use of optimization algorithms to determine the solar cell parameters. Its precision depends on the application's installation algorithm, the user-defined error function, and the primary values of the parameters to be installed.

Ismail et al. (2013) and Jervase et al. (2001) used two models (distinct diode prototypical and dual diode prototypical) and three types of PV elements (monocrystalline, polycrystalline, and thin-film) and studied the effect of partial shading on the PV module, to simulate the parameter using Matlab-Simulink [6, 7]. The results obtained from Matlab-Simulink were compared with the results processed by the manufacturer's data sheet and were acceptable. They employed the genetic algorithm to extract the optimal parameters from the photovoltaic module. Ramoji et al. (2014) and Ramoji1 and Kumar (2014) used the GA algorithm optimization technique to optimize the size and applied it to reduce the total cost $[8,9]$. The suggested hybrid energy system consisted of PV panels, a wind turbine, and a storage battery. The result demonstrated that the GA was converging very well. Rodriguez (2017) used a single-diode with five parameters, such as, Iph, I sat, $\eta$, Rs, and Rh. These parameters changed with solar radiation and temperature; hence, the genetic algorithm was used to categorize these parameters and a monocrystalline PV panel was used. The major aim of this technique was to acquire a number of factors for dissimilar ecological circumstances, deprived of appliance, and slightly oversimplified. In this article has been emphasized that wholly the considerations alteration. To be exact, it has been displayed that $\eta$, Rs, and Rh presented important dissimilarities in the climatic surroundings. The chart of Rh displayed that its level is powerfully nonlinear with relevance given to irradiance and temperature variations; and also to dirtying, aging, degradation, etc. The values of the parameters within the PV model will settle for a sudden drift, so the recommended methodology may be used as an orientation for pinpointing a purpose, because of its ability to use only five operating points for accurately identifying all parameters of the single-diode model. Zagrouba et al. (2010) studies, depend on the approach of the genetic algorithm to identify the parameters of the PV cell and PV module (Is, Iph, Rs, Rash, and n) [11]. These parameters are used to find maximum power. They used the Pasan's software to obtain the parameters of cells and used the GA to obtain the cell electrical parameters from the determined I-V curve. Then it compared these results with those obtained by using the Pasan's software. Simulation results offered that the accuracy of the fitting approach, in the case of solar cells, was better than that of the solar modules, where the values of the minima were shown to be equal to $0.000256 \mathrm{~A} 2$ for the solar cell and $0.0676 \mathrm{~A} 2$ for the module. Eimhjellen (2018) developed an algorithm for calculating the optimal solution for the design of a solar farm with fixed panels [12]. Ayman et al. (2017), Rahmani et al. (2018) and Pereira and Aelenei (2019) presented an evaluation of the state-of-the-art scientific accomplishments for using Artificial Intelligence (AI) techniques in Photovoltaic (PV) structures. It analysed the role of AI algorithms in modelling, sizing, control, fault conclusion, and output assessment of PV systems [13-15].

In this study, the behavior of solar cells and modules under numerous operating conditions will be determined effectively, once their intrinsic parameters are measured accurately and are calculable. The aim is to simulate the current-voltage (I-V) characteristics, a point supported on genetic algorithms by Matlab. The plan is to extract the optimum potency of the photovoltaic panel and to enhance the accuracy of the solar cell parameters, which can be gained by exploitation of direct techniques and an experimental study. The idea is that the formulate of photovoltaic cell effectiveness, extraction, and optimization problems of the single diode model, wherever the greatest equation of the current is utilized in genetic algorithms, and also to introduce minimum and maximum assessment, such as, a shunt and a series of resistance extracted by mathematical equations. Subsequently the examination will give the efficiency gained from the genetic algorithmic program, along with the efficiency gained from experimental study. 


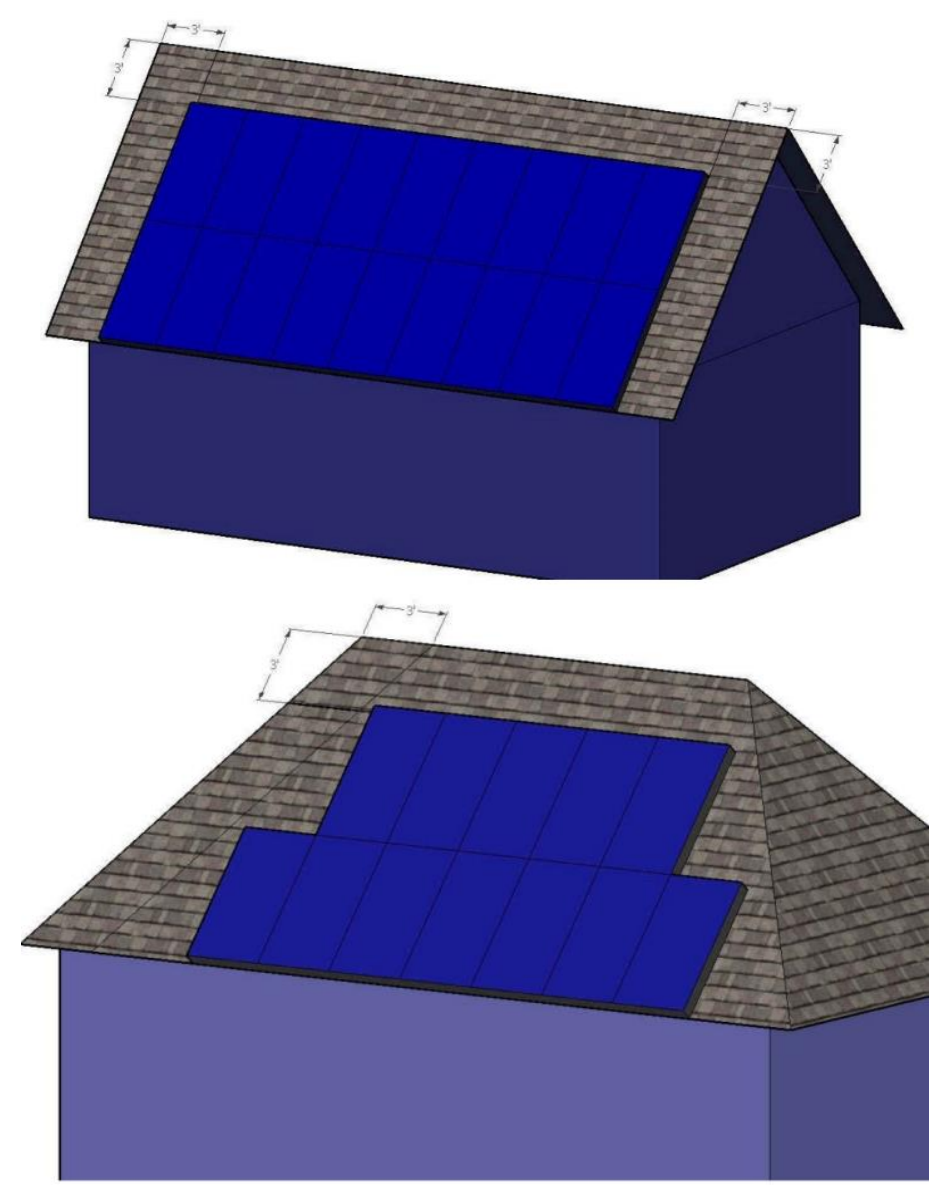

Figure 1. PV location on the roof [16]

\section{Mathematical Modeling of PV Module}

The single-diode model has been used to investigate the relation between voltage $\mathrm{V}$ and the current $\mathrm{I}$ in Equation 1 , it is the main equation that used in genetic algorithm, as given by El Tayyan (2015) [17], the modeling of the single diode corresponding circuit of a PV device is shown in Figure 2.

$$
I=I_{p h}-I_{o}\left(\exp \left(\frac{V+R_{S} I}{a V t}\right)-1\right)-\frac{V+R_{S} I}{R_{s h}}
$$

The PV model can calculate the output power by the simplest form Hashim and Talib (2018) using Equation 2 [18]:

$$
P=I V=\left[I_{p h}-I_{o}\left(\exp \left(\frac{V+R_{S} I}{a V t}\right)-1\right)-\frac{V+R_{S} I}{R_{s h}}\right] V
$$

The diode quality factor $a$. It is equal 1.2 for monocrystalline solar cell [19]. The efficiency of a PV panel is defining the relation of the output power to the input solar power:

$$
\eta=\frac{p}{G \cdot A}
$$

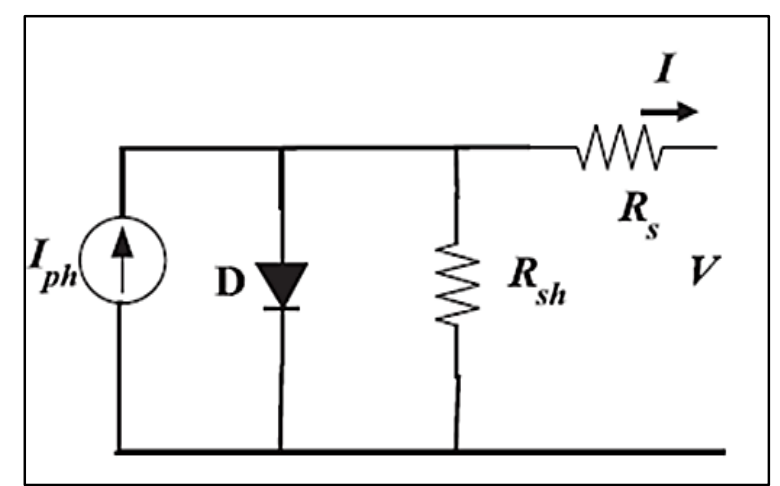

Figure 2. The single-diode model comparable circuit of a PV cell [20-22] 


\section{The Genetic Algorithm}

Genetic algorithms (GAs) are natural galvanized algorithms that support the thought of Darwinian evolution, which embraced the Associate Degree Format Method. The basic components common to all GAs are: a fitness function for optimization, representational choice, crossover, and mutation operators [23] .To deal with the I-V curves digitally, an approach was prepared and the procedure was based on the genetic algorithm (GAs); Equations 1 to 3 were used, minimum and maximum values of series resistance were entered, shunt resistance, voltage, solar radiation, and photo current were generated, to obtain the best value for PV panel efficiency that competed with the experimental one. The Genetic Assembly began by generating an initial set of random probable resolutions (chromosomes) of the problems that had to be improved [24].

Each chromosome was consequently weighed through an adaptive function, to describe the validity of every potential explanation [25]. Next, the genetic agents were applied toward generating novel children; the choice to determine which fathers would be introduced to the new generation according to their adaptive values. Crossover was later used for new atomic products by regrouping data from the parents selected in the preceding stage. The mutation was applied to a variety of populations by changing the genetic structure of some people according to the rate of mutation to obtain a new individual with an ideal specification [23], one can review the genetic program flow chart in Figure 3, which illustrates the basics of its operation. The optimization of multiple-variables of the selected design parameters in a singlefamily building, in temperate climate conditions was implanted by Ferdyn-Grygierek, and Grygierek (2017) [26] which analyzed the inspiration of four categories of windows, their dimension, construction, alignment, isolation of outside walls, rooftops, ground floor, and infiltration on the life cycle costs (LCC). Finaly the optimal decision of the design parameters was implemented by using genetic algorithms by coupling the building performance simulation program EnergyPlus with optimization of the environment.

Li et al. (2017) reached to a fact that Genetic Algorithm (GA) is one of the universally used optimization algorithms for building applications and presented future guidelines for building investigation communal on in what way to put on GA for the optimization of building energy [27].

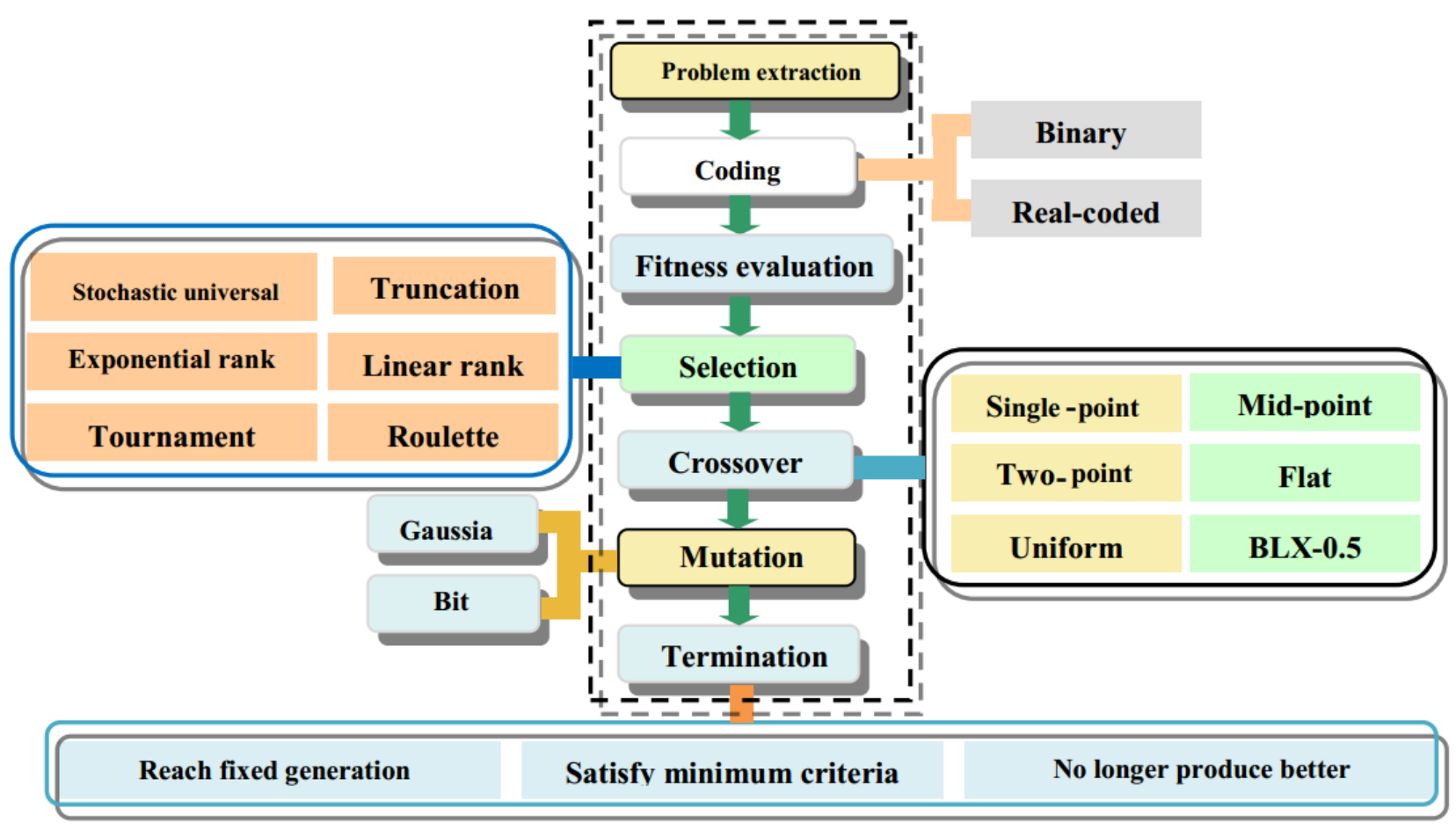

Figure 3. Flowchart of GA. Chief Process is in dashed box, others are the election approaches for each process [27]

\section{Experimental Work}

The experimental setup of the system is explained in Figure 4, the Monocrystalline-Si solar PV module, which has an area of $0.282 \mathrm{~m}^{2}$. Detailed specifications of the PV panel are explained in Table 1; the solar module analyzer measures the current, voltage, fill factor, and efficiency of the PV module. The temperature sensor has been utilized to measure the module temperature, solar power meter is utilized to measure the global radiation incident on the PV module and put it in the same tilt angle of the monocrystalline PV $32^{\circ}$, toward the south. 


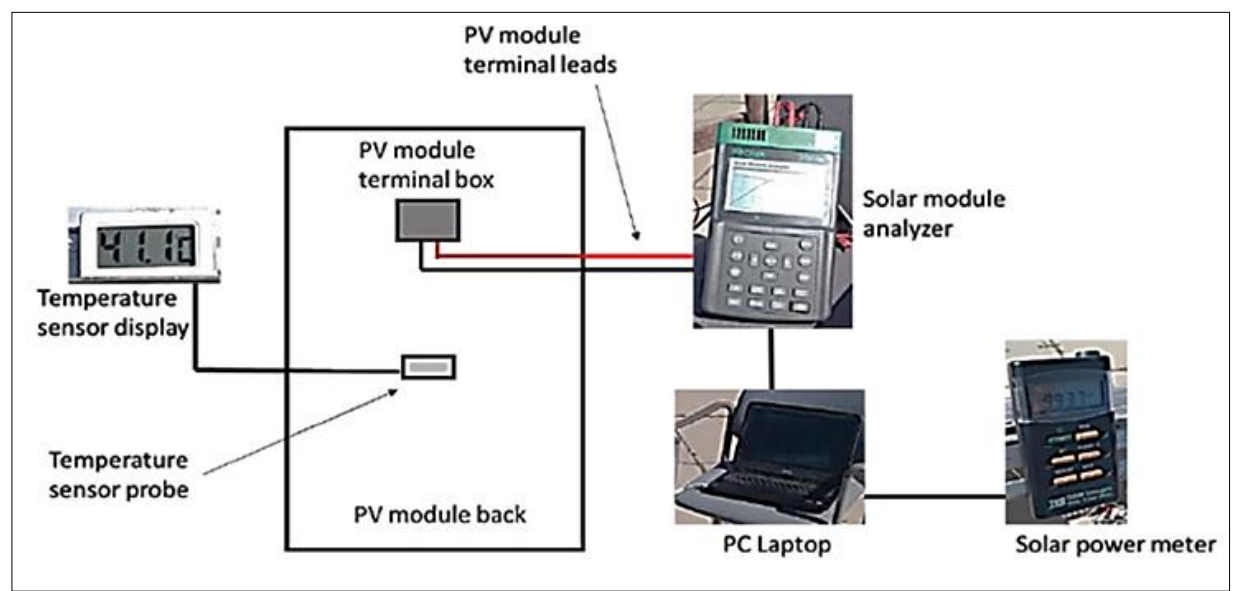

Figure 4. The experimental Setup

Table 1. Module specifications at STC as existing by the industrialist

\begin{tabular}{lc}
\hline Specification of the manufacturer & Value in units \\
\hline Rated power & $30 \mathrm{~W}$ \\
Voltage At Maximum Power (Vmax) & $17 \mathrm{~V}$ \\
Current At Maximum Power (Imax) & $1.76 \mathrm{~A}$ \\
Open Circuit Voltage (Voc) & $22 \mathrm{~V}$ \\
Short Circuit Current (Isc) & $1.9 \mathrm{~A}$ \\
Normal Operation Cell Temperature & $25^{\circ} \mathrm{C}$ \\
Module weight & $3.5 \mathrm{Kg}$ \\
Area & $0.282 \mathrm{~m}^{2}$ \\
Ns & 36 \\
\hline
\end{tabular}

\section{Results and Discussion}

\subsection{Experimental Results}

The Experimental Results show the efficiency of the PV module on solar radiation $\left(\mathrm{G}=500 \mathrm{~W} / \mathrm{m}^{2}\right)$ for four months in Table 2. It shows the efficiency of the PV module between $10.8 \%$ and $15.7 \%$. Figure 5 shows the experimental result taken from the solar module analyzer.

Table 2. The experimental result of radiation $\mathbf{G}=500 \mathrm{~W} / \mathrm{m}^{2}$

\begin{tabular}{ccccccccc}
\hline Month & $\mathbf{T c} /{ }^{\circ} \mathbf{C}$ & $\mathbf{T a} /{ }^{\circ} \mathbf{C}$ & Pmax /W & Imax /A & Vmax/V & Voc $/ \mathbf{V}$ & Isc & $\boldsymbol{\eta} \%$ \\
\hline Oct. 2017 & 33.8 & 27 & 15.32 & 0.91 & 16.85 & 20.39 & 1.018 & 10.8 \\
Nov. 2017 & 28 & 20 & 22.13 & 1.277 & 17.31 & 20.66 & 1.379 & 15.7 \\
Dec. 2017 & 25 & 17 & 17.08 & 0.917 & 18.1 & 21.49 & 1.004 & 12.1 \\
Jan. 2018 & 21 & 12 & 16.6 & 0.936 & 18.25 & 21.64 & 1.025 & 11.7 \\
\hline
\end{tabular}

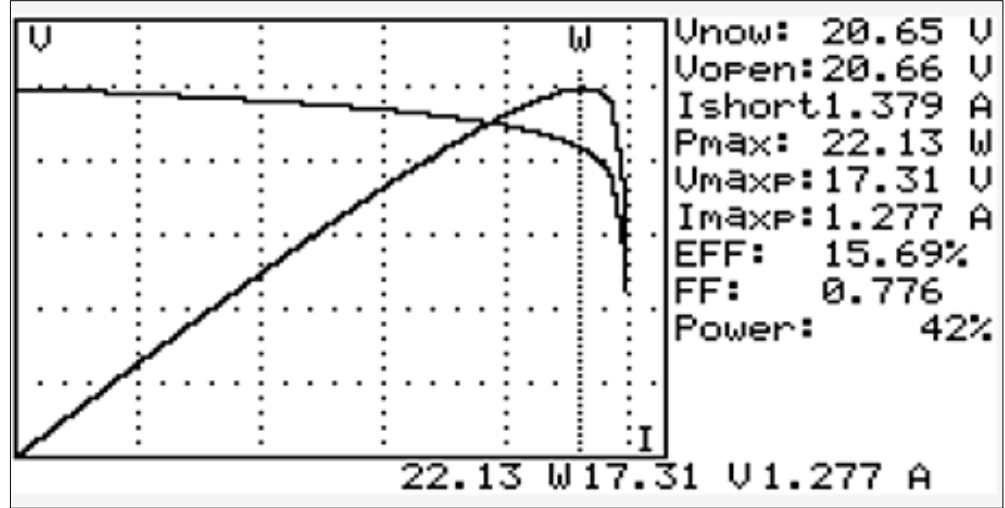

Figure 5. The P-V and I-V curve taken from the solar module analyzer 


\subsection{Genetic Result}

In this section, the efficiency of the solar panel was calculated in the genetic program in the Matlab. Minimum and maximum values of series resistance, shunt resistance, photocurrent generated, the voltage of the PV module, radiation, and cell temperature were entered into the genetic algorithm at boundary conditions. Table 3 shows how the genetic program calculated the values. The optimum efficiency of the solar panel was obtained and was found to be in the range of 0.16 to 0.17 , when the solar radiation was in the range of 500 to $600 \mathrm{~W} / \mathrm{m}^{2}$, such as is displayed in Figures 6 to 8 . The optimum value of efficiency from this table $=17.03 \%$ and when there was an increase in the solar radiation the efficiency increased in this section. This can be observed in Figure 8. According to Figures 6 to 8, and for solar radiation from $600-750 \mathrm{~W} / \mathrm{m}^{2}$, shown in Figures 9 and 10, it was easy to observe that the optimum values of the efficiency obtained by the GA algorithm were, $16.9,17.03$, and $38.8 \%$, respectively.

Table 3. The optimum value of efficiency of genetic program

\begin{tabular}{|c|c|c|c|c|c|c|}
\hline & Rs ( $(\Omega)$ & Iph (A) & $\operatorname{Rsh}(\Omega)$ & Vpv (V) & $\mathbf{G}\left(\mathbf{W} / \mathbf{m}^{2}\right)$ & Te $\left({ }^{\circ} \mathrm{C}\right)$ \\
\hline Max. & 0.3 & 0 & 100 & 0 & 500. & 10 \\
\hline Min. & 1.9 & 1.9 & 500 & 22 & 600 & 60 \\
\hline 1 & 1.7225 & 0.7824 & 100.0000 & 12.5365 & 599.9123 & 15.0581 \\
\hline 2 & 1.6823 & 0.8500 & 100.1145 & 12.0418 & 599.9610 & 15.0077 \\
\hline 3 & 1.6470 & 0.9626 & 100.0000 & 12.3183 & 600.0000 & 15.0000 \\
\hline 4 & 1.7118 & 0.7806 & 100.0518 & 12.5759 & 599.7605 & 15.1063 \\
\hline 5 & 1.6832 & 0.8719 & 101.0099 & 12.2369 & 599.9220 & 15.0000 \\
\hline 6 & 1.6838 & 0.7830 & 100.2250 & 11.1239 & 600.0000 & 15.0773 \\
\hline 7 & 1.6527 & 0.8389 & 100.0000 & 12.6447 & 599.7769 & 15.0000 \\
\hline 8 & 1.6836 & 0.9189 & 100.0000 & 10.6458 & 600.0000 & 15.1225 \\
\hline 9 & 1.6228 & 0.7124 & 100.5751 & 12.1335 & 600.0000 & 15.0000 \\
\hline 10 & 1.6261 & 0.7202 & 100.5979 & 12.1523 & 599.9822 & 15.0354 \\
\hline 11 & 1.6226 & 0.8483 & 100.3501 & 11.6554 & 600.0000 & 15.0452 \\
\hline 12 & 1.6541 & 0.7719 & 100.1105 & 11.7268 & 599.8159 & 15.0696 \\
\hline 13 & 1.6794 & 0.7619 & 100.0000 & 11.4137 & 599.6418 & 15.0000 \\
\hline 14 & 1.6852 & 1.0713 & 102.3651 & 12.2345 & 600.0000 & 15.1276 \\
\hline 15 & 1.6118 & 0.9476 & 100.0000 & 12.1988 & 600.0000 & 15.1722 \\
\hline 16 & 1.5803 & 0.8514 & 100.0000 & 12.3065 & 599.9629 & 15.0000 \\
\hline 17 & 1.6232 & 0.7218 & 100.2687 & 12.2904 & 599.8004 & 15.0058 \\
\hline 18 & 1.6266 & 0.7296 & 100.2915 & 12.3092 & 599.7827 & 15.0412 \\
\hline
\end{tabular}

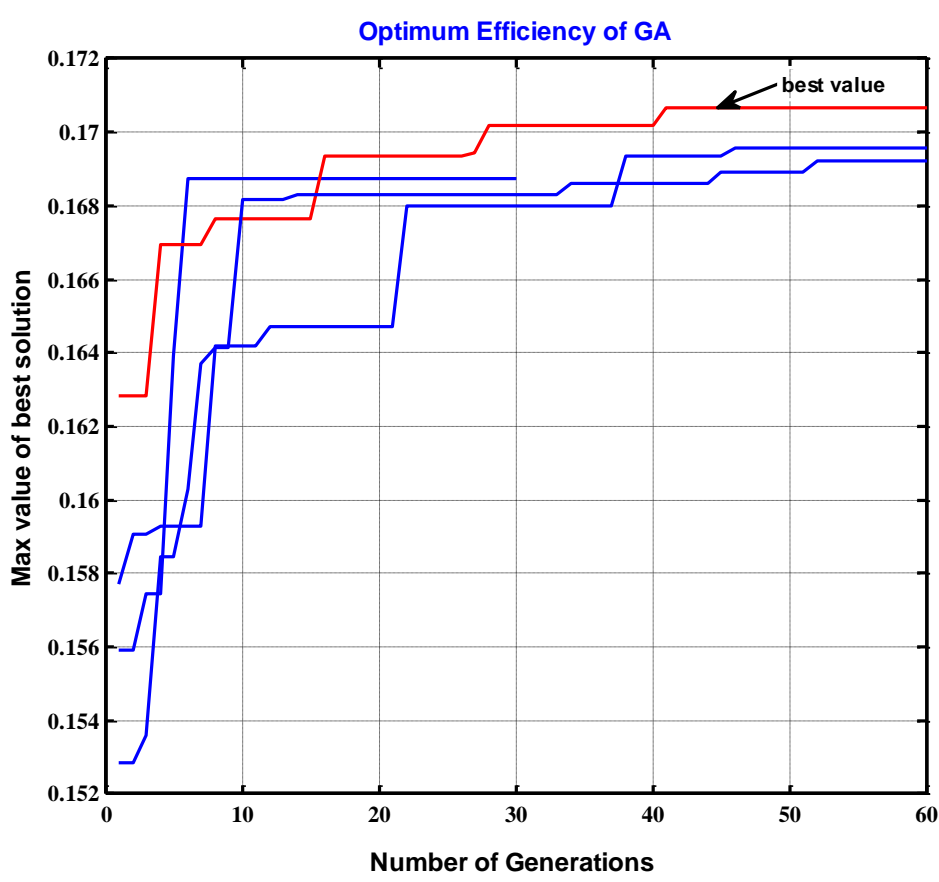

Figure 6. The optimum value of efficiency of radiation $\left(500-600 \mathrm{~W} / \mathrm{m}^{2}\right)$ 


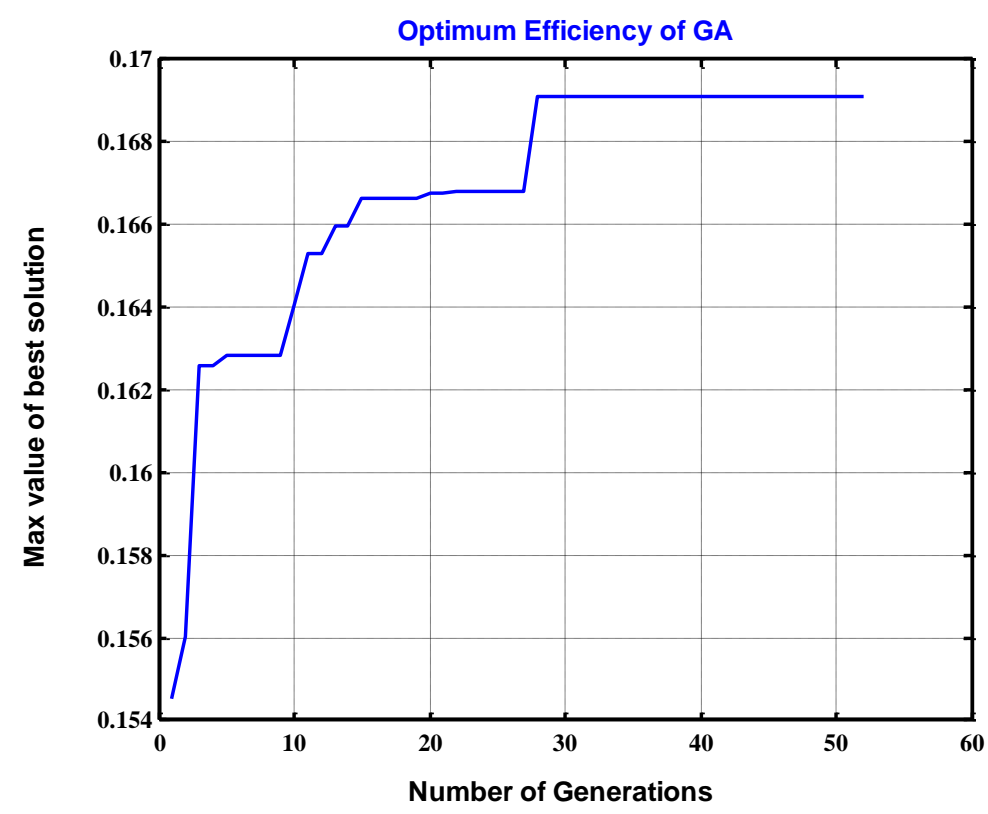

Figure 7. The optimum value of efficiency of radiation $\left(500-600 \mathrm{~W} / \mathrm{m}^{2}\right)$

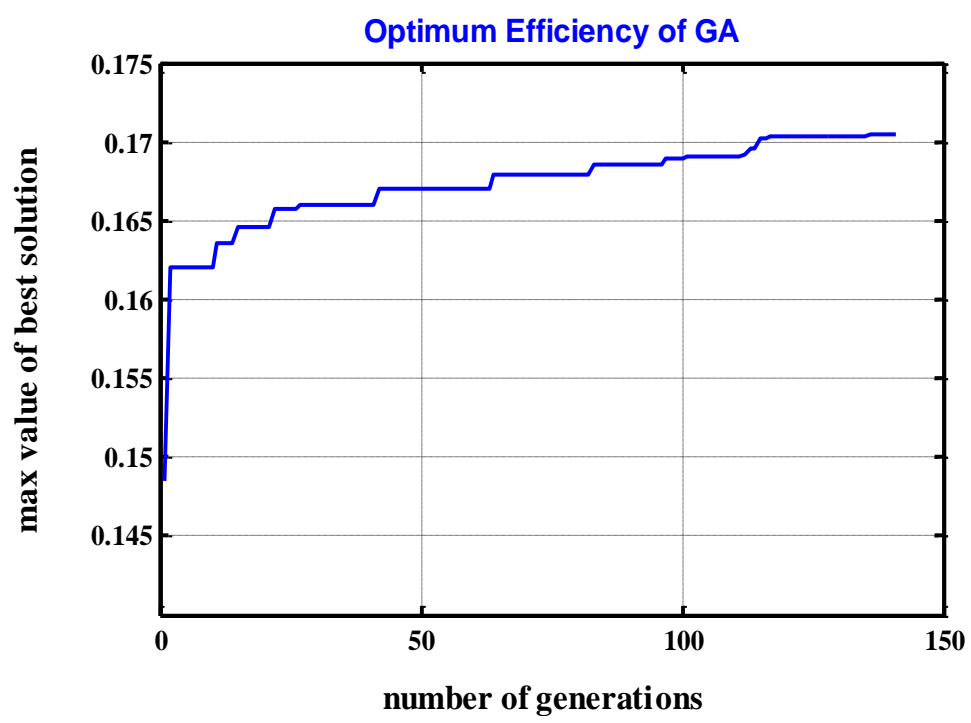

Figure 8: The optimum value of efficiency of radiation $\left(500-600 \mathrm{~W} / \mathrm{m}^{2}\right)$

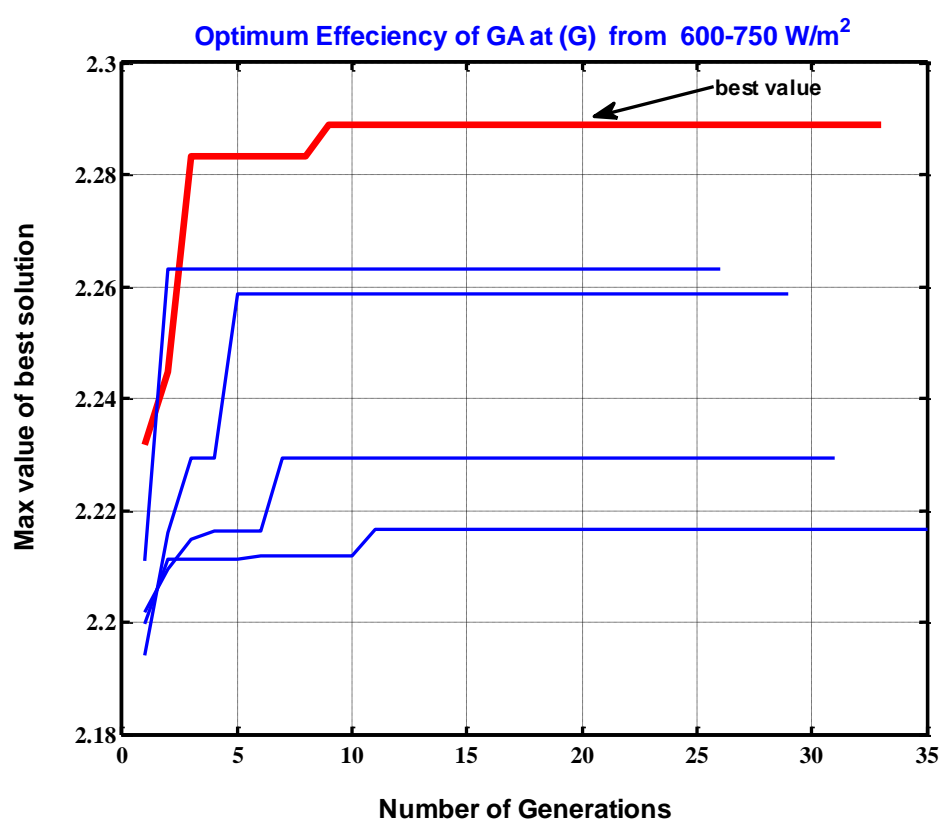

Figure 9. The optimum value of efficiency of radiation $\left(600-750 \mathrm{~W} / \mathrm{m}^{2}\right)$ 
Efficiency of GA (best value) at Radiation $\left(500-750 \mathrm{~W} / \mathrm{m}^{2}\right)$

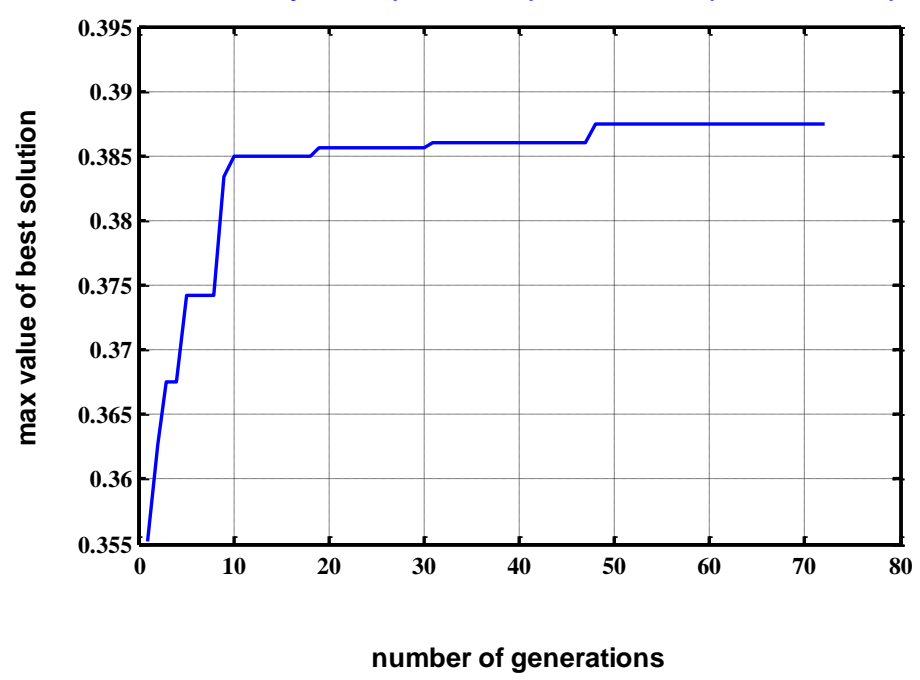

Figure 10. The optimum value of efficiency of radiation $\left(600-750 \mathrm{~W} / \mathrm{m}^{2}\right)$

\section{Conclusion}

In this study, the modeling process was based on the genetic algorithm that had been proposed to obtain the optimal values for solar panel efficiency; a single-diode model was used. The efficiency values extracted by using this algorithm were viable for the entire range of solar radiation, temperatures, voltage, series resistance, and shunt resistance. The information on the PV module, presented in the manufacturer's data sheet, was the requirement for this approach. The result validation was conducted for the type of PV module technologies, monocrystalline, by comparing it with the result of the experimental study, where the results of the efficiency of the panel, extracted from the genetic algorithm, ranged between $0.16-0.17$, and the results obtained from the experimental study ranged between $0.108-0.157$. This gave an indication of the accuracy and validity of the genetic algorithm.

This application is not confined to monocrystalline solar panels alone; it can be applied to all solar panels and can be utilized to extract all solar panel parameters. The slight differences between the experimental results and genetic optimization are due to the temperature variation effects, significantly on the output voltage, as the open circuit voltage has a logarithmic relationship with the inverse of the reverse saturation current, which is greatly influenced by temperature.

\section{Conflicts of Interest}

The authors declare no conflict of interest.

\section{References}

[1] Nibal Fadel Farman, Zeina Ali Abdul Redha and Shaymaa A. Mahdi. "Optimization the Efficiency of Continuous Solar Adsorption Refrigeration System with Genetic Algorithm." 2nd International Conference on the Applications of Information Technology in Developing Renewable Energy Processes \& Systems (IT-DREPS), (December. 2017):6-7. doi: 10.1109/ITDREPS.2017.8277821.

[2] Latief, Y., M A Berawi, A B Koesalamwardi, L, S R Supriadi. "Near Zero Energy House (NZEH) Design Optimization to Improve Life Cycle Cost Performance Using Genetic Algorithm. IOP Conf. Series: Earth and Environmental Science 124 (March 2018): 012006. doi:10.1088/1755-1315/124/1/012006.

[3] Fatima Harkouss, Farouk Fardoun, Pascal Henry Biwole. "Multi-Objective Optimization Methodology for Net Zero Energy Buildings.” Journal of Building Engineering 16 (March 2018): 57-71. doi:10.1016/j.jobe.2017.12.003.

[4] Alima, D. "Sensitivity of Solar Photovoltaic (PV) Efficiency to Climate Change and Dust: Comparative Study between Niamey and Abidjan."WASCAL. (November 2015). Master Thesis in Climate Change and Energy Delivered by: Universitat Abdou Moumouni - Niamey, Niger.

[5] Zaihidee, F, M., Mekhilef, S., Seyedmahmoudian, M. and Horan, B. "Dust as an unalterable deteriorative factor affecting PV panel's efficiency: Why and how.” Renewable and Sustainable Energy Reviews 65 (November 2016): 1267-1278. doi: 10.1016/j.rser.2016.06.068.

[6] Ismail, M.S., Moghavvemi, M. and Mahlia, T.M.I. "Characterization of PV Panel and Global Optimization of its Model parameters using Genetic Algorithm," Energy Conversion and Management. 73 (September 2013):10-25. doi:10.1016/j.enconman.2013.03.033. 
[7] Jervase, J.A., Bourdoucen, H. and Al-Lawati, A. "" Solar Cell Parameter Extraction Using Genetic Algorithms." Measurement Science and Technology 12 (November 2001): 1922-1925. doi:10.1088/0957-0233/12/11/322.

[8] Ramoji, S, K., Rath, B, B. and Kumar, D, V. "Optimization of Hybrid PV/Wind Energy System Using Genetic Algorithm (GA)." International Journal of Engineering Research and Applications 4 (January 2014): 29-37. ISSN: 2248-9622.

[9] Satish Kumar Ramoji1 and B. Jagadish Kumar. “ Optimal Economical sizing of a PV-Wind Hybrid Energy System using Genetic Algorithm and Teaching Learning Based Optimization. " International Journal of Advanced Research in Electrical, Electronics and Instrumentation Engineering 3 (February 2014): 7352-7367: ISSN: 2278 - 7798.

[10] Rodriguez, J, D., Petrone, G., Paja, C, A. and Spagnuolo, G. “A genetic Algorithm for Identifying the Single Diode Model Parameters of a Photovoltaic Panel." Mathematics and Computers in Simulation.131 (October 2017): 38-54. doi:10.1016/j.matcom. 2015.10.008.

[11] Zagrouba, M., Sellami, A., Bouaı"cha, M. and Ksouri, M. "Identification of PV Solar Cells and Modules Parameters Using the Genetic Algorithms: Application to Maximum Power Extraction." Solar Energy 84 (May 2010): 860-866. doi:10.1016/j.solener.2010.02.012.

[12] Einar Eimhjellen," Optimal design of photovoltaic power plants. " Master thesis in Applied and Computational Mathematics. Department of Mathematics, University of Bergen Spring 2018.

[13] Ayman Y., Mohammed El-Telbany, and Abdelhalim Z. "The Role of Artificial Intelligence in Photo-Voltaic Systems Design and Control: A review." Renewable and Sustainable Energy Reviews 78 (October 2017): 72-79. doi:10.1016/j.rser.2017.04.046.

[14] Rahmani, Javad and Sadeghian, Ehsan and Dolatiary, Soheil. "Comparison between Ideal and Estimated PV Parameters Using Evolutionary Algorithms to Save the Economic Costs.” International Research Journal of Engineering and Technology (IRJET) 05, (October 2018): 208-216.

[15] Ricardo Pereira, Laura Aelenei. "Optimization assessment of the energy performance of a BIPV/T-PCM system using Genetic Algorithms.” Renewable Energy 137 (July 2019): 157-166. doi:10.1016/j.renene.2018.06.118.

[16] Legacy, City of Irvine "Solar Photovoltaic System for Single Family Dwelling Community Development." Available online: https://legacy.cityofirvine.org/civica/filebank/blobdload.asp?BlobID=13485 (Accessed on 1 May 2019).

[17] El Tayyan, A. A. “ An Approach To Extract The Parameters Of Solar Cells From Their Illuminated IV Curves Using The Lambert W Function." Turkish Journal of Physics 39 (January 2015): 1-15. doi:10.3906/fiz-1309-7.

[18] Emad Talib Hashim and Zainab Riyadh Talib. "Modelling and Simulation of Solar Module performance using Five Parameters Model by using Matlab in Baghdad City." Journal of Engineering, (October 2018): 10-15. doi:10.31026/j.eng. 2018.10 .02

[19] Vergura, S. “A Complete and Simplified Datasheet-Based Model of PV Cells in Variable Environmental Conditions for Circuit Simulation." Energies 9 (April 2016): 329. doi: 10.3390/en9050326.

[20] Cem Emeksiz, Akif Akbulut, Zafer Dogan, Mehmet Akar. "Optimization of PV Module with Single-diode Model for Tokat Region." International Journal of Research, Science \& Management 4 (June, 2017): 78-85. doi:10.5281/zenodo.802328.

[21] Hashim, E. T., and Hussien, S. A. M. "Synchronous Buck Converter with Perturb and Observe Maximum Power Point Tracking Implemented on a Low -Cost Arduino-microcontroller.” Journal of Engineering 24 (February 2018): 16-33. ISSN: 17264073 25203339.

[22] Emad Talib Hashim and Akram Abdulameer Abbood. "Temperature Effect on Power Drop of Different Photovoltaic Modules." Journal of Engineering, (May 2016): 129-143.

[23] Lamini, C., Benhlima, S. and Elbekri, A. "Genetic Algorithm Based Approach for Autonomous Mobile Robot Path Planning, Procedia Computer Science 127 (2018): 180-189. doi:10.1016/j.procs. 2018.01.113.

[24] Khan, M, W., and Alam, M. "A Survey of Application: Genomics and Genetic Programming, a New Frontier." Genomics 100 (August 2012): 65-71. doi:10.1016/j.ygeno.2012.05.014.

[25] Marandi, R, G., and Smith, B, K." Fluid Genetic Algorithm (FGA). ” Journal of Computational Design and Engineering 4 (April 2017): 158-167. doi:10.1016/j.jcde.2017.03.001.

[26] Joanna Ferdyn-Grygierek, and Krzysztof Grygierek. "Multi-Variable Optimization of Building Thermal Design Using Genetic Algorithms." Energies 10 (October 2017): 1570. doi:10.3390/en10101570.

[27] Tiejun Li, Guifang Shao, Wangda Zuo and Sen Huang. "Genetic Algorithm for Building Optimization - State-of-the-Art Survey." Proceedings of the 9th International Conference on Machine Learning and Computing (ICMLC 2017), (February 2017). doi:10.1145/3055635.3056591. 